\title{
Applications of Microdroplet Technology for Algal Biotechnology
}

\begin{abstract}
BACKGROUND: Microfluidics allows manipulation of small volumes of fluids through channels with dimensions of tens to hundreds of micrometres. Microdroplet technology is a form of microfluidics in which small (10-200 $\mu$ m diameter) monodisperses aqueous droplets are generated, manipulated and analysed in various ways. This multidisciplinary field provides an exciting new platform for single-cell studies of both eukaryotic microalgae and cyanobacteria, with considerable potential for enhancing algal biotechnology.

METHODS: Growth of several species of microalgae has been studied in detail using microfluidics and microdroplets, and individual cells have been screened and sorted according to lipid content or ethanol production. Here we provide an overview of the devices, and the range of technological advances that are being pursued.

CONCLUSIONS: Microdroplet technology is an exciting technology platform that can be used in a variety of applications, including monitoring of growth characteristics at the single-cell level and high-throughput screening of algal populations. Microdroplet platforms are being developed that will allow determination of individual cell characteristics to allow screening across a population, and thus to identify and select candidate cells for biotechnological feedstocks. As the potential of this emerging technical platform is recognized, the technology will become more accessible, so that it can soon be adopted and used by researchers, without the need for specialized prior knowledge of microfluidics or expensive equipment. The platform is amenable for use with species of both microalgae and cyanobacteria.
\end{abstract}

Keywords: microalgae - microfluidics - microdroplets - screening - fluorescence - biofuels.

\section{INTRODUCTION}

There is increasing interest in using eukaryotic microalgae and prokaryotic cyanobacteria for a range of biotechnological purposes, for example, for the production of pigments, vitamins, fatty acids, or bulk chemicals to replace products from fossil fuels. With the advent of tools for their genetic manipulation, microalgae are being investigated as sources of novel high value molecules, such as therapeutic recombinant proteins. These organisms can be grown at scale in controlled conditions like other biotechnological hosts. However because they are photosynthetic, their cultivation might be more sustainable than heterotrophic yeasts or bacteria because they do not need a supply of organic carbon for growth. Moreover, microalgae and cyanobacteria grown for industrial purposes do not compete with agricultural crops for land. They require less water than land crops, and could use waste $\mathrm{CO}_{2}$ from industrial processes as a carbon source [1-3].

The most obvious application of microalgae and cyanobacteria in biotechnology is as a potential source of high-value lipids and biofuels. They have fast growth rates and can accumulate large amounts of triacylglycerols (TAGs), which can be converted to biodiesel by transesterification $[1,2]$. TAGs are stored within individual cells in lipid droplets. Production of TAGs in microalgae is often induced by nutrient stress, such as phosphate or nitrogen deprivation, and under these conditions, several species can produce over $70 \%$ of their dry weight as TAGs [3]. Nonetheless, there are several challenges that must be overcome to transfer promising production systems from the laboratory to industrial scale to enable them to become a commercial reality [1]. These include identifying strains of algae that accumulate high levels of desirable products and establishing appropriate growth conditions to maximise yields. In addition, methods for growing microalgae at large scale, harvesting the microscopic cells, and extracting intracellular TAGs need to be improved.

Although it may seem paradoxical to scale down to a single cell level to tackle problems during scale up, in many cases useful insights can be made by studying these organisms at a single-cell level. Using bulk techniques, researchers assume that all cells in a culture behave identically to a hypothetical 'average cell.' However, even a genetically-identical population is likely to be heterogeneous. Cell characteristics are governed by a series of biological processes, each of which possesses a degree of stochasticity [4]. The combined results of a stochastic processes can generate a population of cells with a wide 
range of measurable phenotypes, which will not be seen when they are investigated in bulk.

High-throughput single-cell fluorescence technologies have been used to show that isogenic cultures of both bacteria and yeast can be highly diverse in terms of gene and protein expression [5-7]. Likewise, single cell analyses reveal that genetically identical cultures of bacteria and algae can display a wide range of cell sizes and individual growth profiles [7-9]. Single-cell studies can also be applied to mixed populations as a way of identifying sub-populations or even individual cells with particular properties or characteristics that may be useful in biotechnological applications [10].

In this review, we give a brief introduction to microfluidics and then describe recent methods to study microalgae and cyanobacteria at the single-cell level in microdroplets, and show how these approaches are relevant to applications in biotechnology.

\section{MICROFLUIDIC AND MICRODROPLET TECHNOLOGY}

Microfluidics is a multidisciplinary field at the intersection of physics, engineering, chemistry and biology. It allows small volumes of fluids to be manipulated and analysed as they flow through a network of specifically designed microchannels. It has the advantage of low reagent-consumption and high sensitivity, and the potential to revolutionise the study of biological processes in a miniaturised 'lab-on-a-chip' format $[11,12]$. A microfluidic device can be quickly designed by Computer Aided Design (CAD) and then fabricated relatively straightforwardly and cheaply using soft lithography [13]. Figure 1A shows a schematic of a microfluidic chip: a PDMS device with patterned microchannels containing inlets and outlets for sample treatment has been sealed to a glass substrate.

Microfluidics allows the microenvironment of individual cells to be tightly controlled. This feature of the technology has been exploited to measure the response of individual cells to precise spatiotemporal concentration gradients, mechanical forces and temperatures [14]. Cells can be confined and isolated into microchambers and studied over longer periods of time, often to study cell growth and division [15]. The properties of individual cells can be analysed at high-throughput. Electrodes can be embedded into a device to facilitate cell characterisation (by cell counting, electrochemical detection) [16], or manipulation (electroporation, cell lysis or dielectrophoresis by an applied electric field) [17]. Precise temperature control can be applied to microfluidic devices, either using electrodes [18], or by flowing temperature controlled fluids through different layers of a device [15].

Individual cell research in microfluidic devices has focussed on bacteria, yeasts and animal cells, but can be extrapolated to algae. Specifically, Figure 1B is an example of a microfluidic device that was used for screening based on the morphological characteristics of different alga species using an optofluidic device [19].

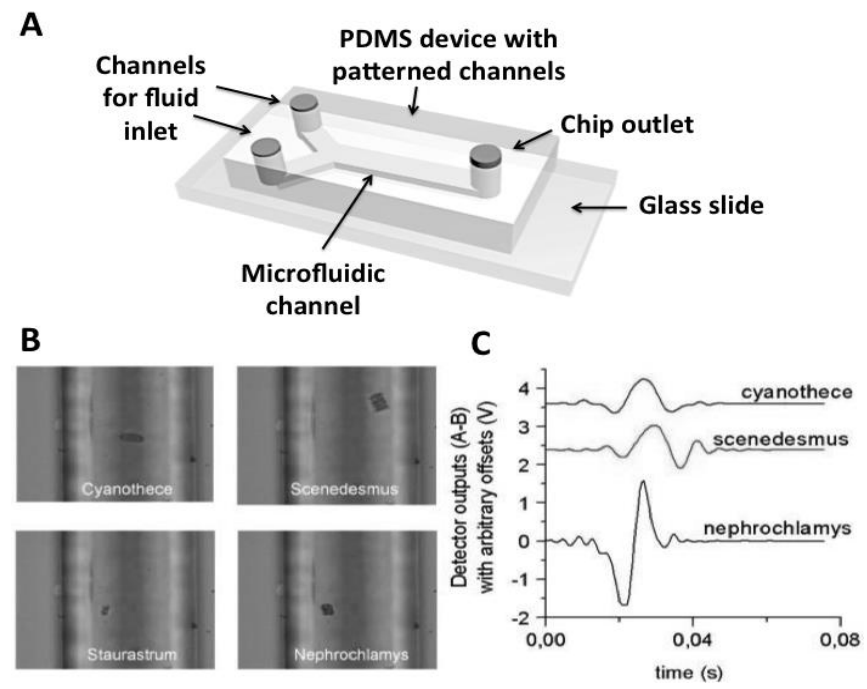

Figure 1. A) Example of a microfluidic device. Photolithography is the most widely used technique for the fabrication of microfluidic channels, and PDMS and glass are usually the chosen substrates for patterning the design. The microfluidic chip is made up from inlet channels for the pumping of the solutions, a delay channel in which screening is usually performed, and an outlet channel for the extraction of the pumped fluids. In order to close the channel features, the PDMS or glass component where the channels have been patterned, is sealed to another glass slide or a plain piece of PDMS after plasma treatment; B) Screening of different species of algae using an optofluidic device containing a waveguide. Images taken on the fly by the camera overlooking the fluidic channel and the different geometry of the screened species; C) the sample signals rising above a set threshold that in turn triggered the sample imaging. $\mathrm{B}$ and $\mathrm{C}$ are reproduced with permission of Ref. [19]

Microdroplet technology is a sub-set of microfluidics [20,21]. Microdroplets are small (typically 20-100 $\mu \mathrm{m}$ diameter) aqueous droplets, which are carried in an oil stream within a microchannel of a microfluidic device. Advantages of this technology include compartmentalization (individual cells can be isolated in discreet droplets), monodispersion (each cell is cultured in a uniform environment, so comparisons between droplets can be quantitative), low reagent consumption (droplet volumes are typically femtolitres to nanolitres) and high throughput analysis (droplets can be analysed at up to $2 \mathrm{kHz}$ ) [20]. As individual cells can be encapsulated into these droplets, they can either be studied in isolation in fine detail, or cell-cell interactions within or between droplets can be analysed.

Many different microdroplet devices have been designed and used to allow analysis of individual cells and biological processes [21]. Furthermore, different droplet manipulations such as incubation, splitting, fusion, dilution, picoinjection or sorting can be integrated either in the same chip, or by connecting multiple devices [22]. Figure 2 is a schematic representation of the main operations that can be performed 

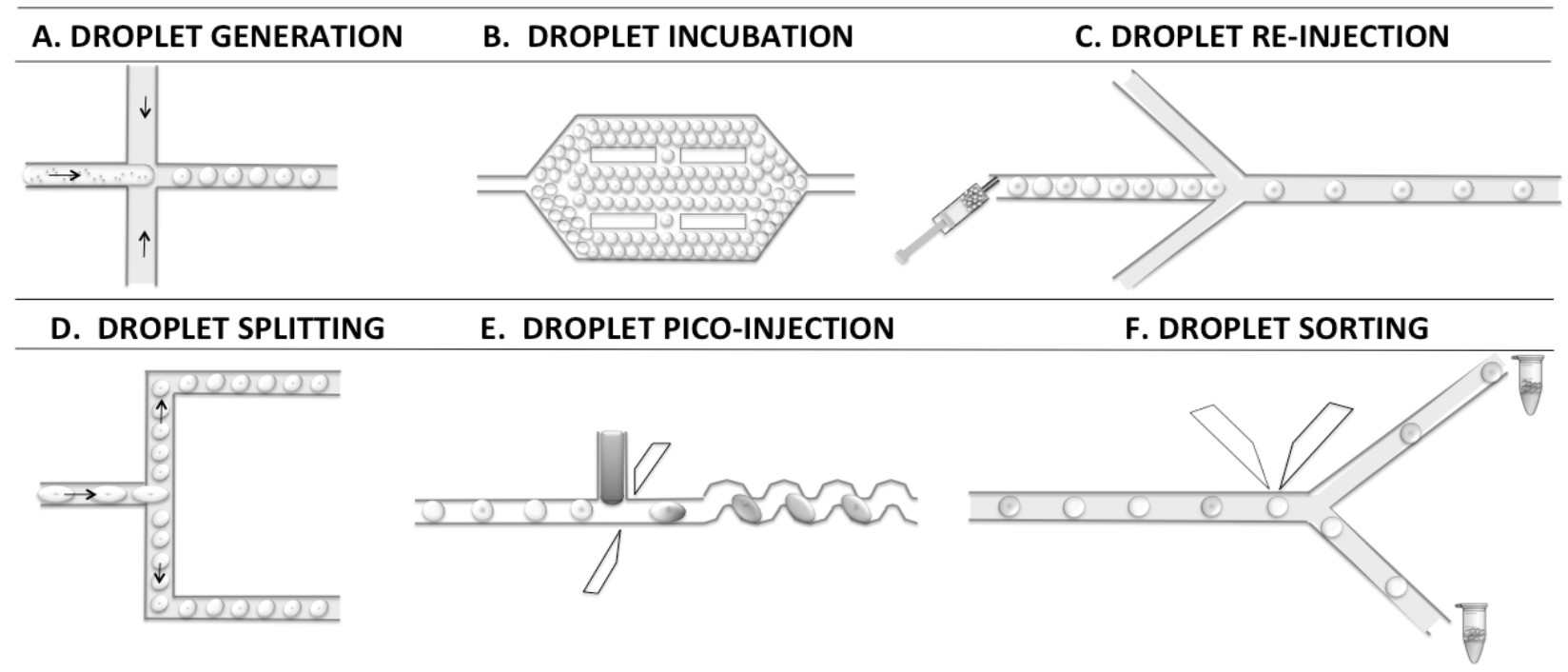

Figure 2. Schematic representation of possible microdroplet operations: A) Picoliter droplets are formed when a stream of water is periodically broken by two confluent streams of oil; B) Microdroplets can be maintained in a reservoir in order to allow cell growth and metabolite accumulation in the droplets for further analysis; C) Droplets, stored either off-chip or onchip as in (B) are pumped in a microfluidic channel and spaced with two streams of oil to adjust microdroplets flowing frequencies on demand; D) Microdroplets can be split in order to decrease volumes for assay performance or for sample replicate production; E) Picoliter volumes of reagents are injected into each droplet by using extra channels and electrodes to disrupt the surface tension of droplets; F) Droplets are sorted on-chip based on their contents by using a combination of lasers and electrodes. Droplets showing a specific signal over a threshold are drawn into the 'positive' (top) channel, while droplets being 'negatives' flow to the bottom channel.

in microdroplets. The chip is designed for the desired operation, which is directly related to conventional lab-bench protocols. Droplet generation (Figure 2A) happens when two confluent streams of oil cut perpendicularly a stream of aqueous fluid. Adjusting parameters such as channel size and shape, or fluid speed and viscosity, it is possible to vary droplet size on demand. This operation is especially important for cell encapsulation. The aqueous stream can be medium for cell culture, so when the droplet is formed the cells are trapped inside. Further operations with the encapsulated cells are also possible. Incubation of cells in droplets is done in chambers called reservoirs (Figure 2B). The droplets can be held still, so quantitative tracking of single cells can be carried out to give kinetic information. The cells remain viable because PDMS allows for gas exchange.

Stable cell-containing droplets can be stored for short periods (hours) in delay lines [23], and for longer times (up to 30 days) either off-chip or within microfluidic devices either in individual droplet traps [24] or reservoirs [25]. Encapsulated cells can be monitored over their entire growth cycle within droplets. Microscopy allows the number, size and shape of individual cells to be monitored as they reside in the device. Intact droplets can be recovered and could be used in different microfluidic processes (Figure 2C) or deemulsified to return cells to bulk growth conditions.
Droplets can be separated to allow different operations on duplicate droplet populations (Figure 2D). It is worth highlighting the pico-injection operation (Figure 2E). Picoinjection allows the addition of reagents to a pre-formed droplet, for example for the analysis of metabolites that have been secreted to the droplet environment by the cell during the incubation step.

Droplet contents can be analysed using techniques including laser-induced fluorescence (LIF), UV-visible spectophotometry, mass-spectrometry, liquidchromatography or Raman and SERS spectroscopy [26]. Since cells are encapsulated into droplets of small volumes, any molecules that are secreted or released from the cell can quickly accumulate to detectable concentrations, allowing highly sensitive detection of droplet components. Laserinduced fluorescence detection is the most commonly used sensing technique for cell analysis and screening in microdroplets. Both the indirect fluorescence due to a specific secreted metabolite (from the cell to the droplet environment) as well as the fluorescence of individual cells, can be studied and screened within a microfluidic chip. This usually requires fluorescent assays or dyes/stains, for extracellular or intracellular identification respectively, to screen metabolites or highlight specific features of cells.

The basic principles of microfluidic screening are as follows: individual cells flow at high frequency past a sensitive detector and the properties of each cell are 
instantaneously measured and recorded. If screening is coupled with sorting, such as the Fluorescence Activated Droplet Sorting platform (FADS) [27], then cells with properties of interest are selected and separated from the rest of the population into a separate collection channel. Cells can be screened and sorted at around $100 \mathrm{~Hz}$ within a microfluidic device. Although this approach is currently lower throughput than traditional Fluorescence Activated Cell Sorting (FACS), in which tens of thousands of cells can

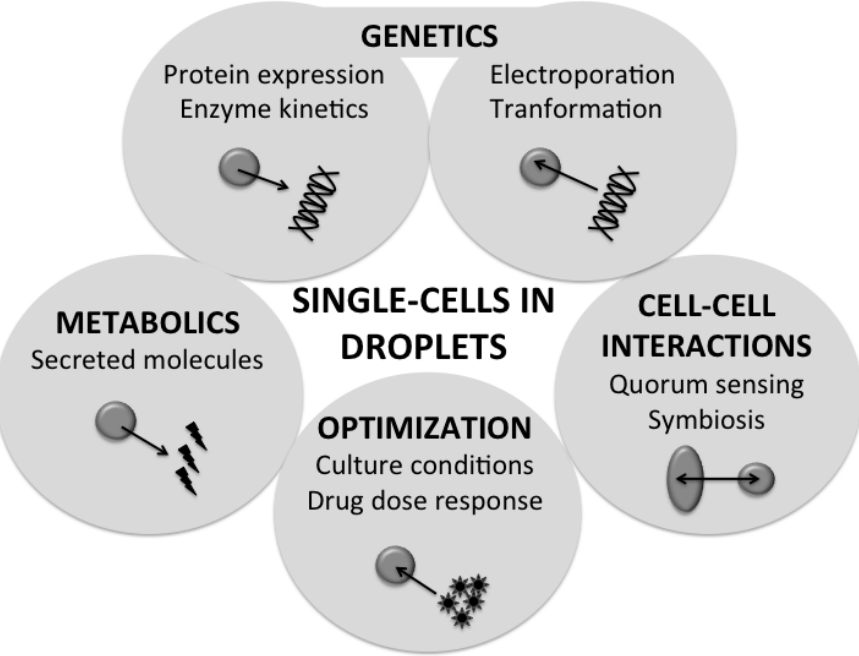

Figure 3. Schematic representation of single-cell manipulations that have been carried out in microdroplets (see text for details).

be analysed per second, the microfluidic platform offers considerable flexibility in terms of the operations with these droplets (as illustrated in Figure 2). Moreover, a key additional functionality is that there is the possibility to recover individual cells in droplets, which can then be further manipulated.

\section{SINGLE-CELL MANIPULATION AND ANALYSIS IN DROPLETS}

A number of single-cell operations and analyses have been performed on cells in microdroplets, so far mainly bacteria and yeast [21] (Figure 3). Cells can be lysed in droplets at specified time-points using a laser, detergent, or a cell-degrading enzyme. Protein expression [28] and enzyme kinetics [29-33] have been studied in both intact and lysed cells in microdroplets. A number of different genetic analyses have been performed on single cells in aqueous droplets [34,35]. For example, Hollfelder and co-workers established a method for the encapsulation and quantification of the expression of GFP from a single DNA template using an in-vitro expression system in droplets [25].

A key feature of compartmentalisation in droplets is the established link between genotype and phenotype, for example allowing directed evolution of enzymes to take place in droplets. In addition, new genetic material can be delivered to individual cells in droplets, by both electroporation and chemical transfection [36,37]. Zhan et al. demonstrated the possibility of electroporation of Chinese Hamster Ovary (CHO) cells by encapsulating cells in picoliter droplets and applying an electric pulse. The successful delivery of an EGFP plasmid was achieved by this technique. Genetic transfection of individual target cells in discreet droplets is highly desirable. The long-term aim is to integrate this into longer workflows so that specific cells can be genetically manipulated, stored and then screened within the same discreet droplet.

Secreted molecules, including antibodies [38,39] and metabolites [40,41] from individual cells have been detected in microdroplets. Wang et al. screened a library of Saccharomyces cerevisiae according to the consumption of xylose, and enriched a population of L-lactate producers of Escherichia coli [40]. This screening of both the cell and its microenvironment would not have been possible using FACS, which can only be used to screen for metabolites that remain associated with the cell.

Droplets with varying compositions can be generated to screen cells against a number of conditions. This has been used for drug studies on single cells, to generate doseresponse information [42-44]. Churski et al. [42] were able to assess the toxicity of a range of antibiotics against $E$. coli in droplets.

Microdroplets can also be used to monitor interactions between small numbers of cells in detail, including quorum sensing (QS) [45,46] and symbiotic interactions [47]. Boedicker et al. demonstrated the QS ability of encapsulated Pseudomonas aeruginosa bacteria in droplets. Remarkably, droplets containing as few as one to three cells were able to initiate QS and achieve QS-dependent growth [45].

A large range of organisms have already been studied in microdroplets, including bacteria [48], yeast [24], mammalian cells [49,50], and even the multicellular organism Caenorhabditis elegans [49]. This emerging platform is now being expanded to include microalgae $[8,51]$ and cyanobacteria [41], with exciting implications for the development of microfluidic technology, and expanding the biotechnological potential of these organisms.

\section{MONITORING INDIVIDUAL MICROALGAL CELLS HELD IN DROPLETS}

Single-cell studies using microfluidics allow detailed analysis of individual cell behaviour [52]. Insight into factors that affect and limit single-cell growth and behaviour might be applied to scale-up the growth of algae, both in flask culture in the laboratory, and at industrial scale for algal biotechnology. In fact, the behaviour of individual trapped microalgal cells has been studied using several different microfluidic approaches, trapping small numbers of cells in a range of devices, including microfluidic chambers [53-60] and capsules [61,62]. These are summarised in Table 1 .

Pan et al. developed an experimental platform in which single microalgal cells were encapsulated into droplets and their growth tracked [51]. Droplets were stable and encapsulated cells were monitored for at least 20 days. In all cases, the cells were seen to divide and grow within the droplets (Figure 4). The observed growth rates matched those measured in bulk. The maximum cell density achieved in droplets was higher by about one order of magnitude on average, possibly due to less self-shading. A similar experimental set-up has also been applied to study the 


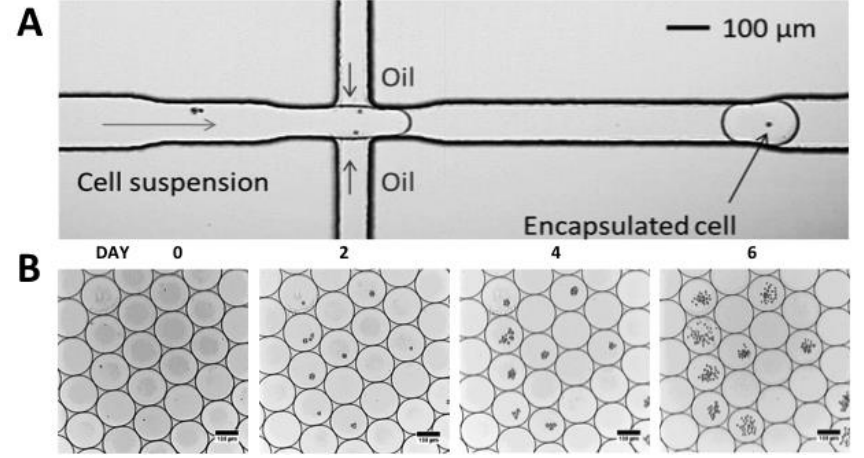

Figure 4. A) Bright field microscopy image of single cell encapsulation in picoliter droplets on a flow-focusing droplet generator; B) Bright-field images showing the increase in the number of cells per droplet at days 0,2,4 and 6 days after inoculation. The image has been taken of the same microdroplets contained in the reservoir for single-cell droplet tracking.

growth of the cyanobacterium Synechocystis sp. PCC6803 in microdroplets [41].

Microdroplets have been used to compare the growth profiles of cells across a population, and investigate population heterogeneity, even within an isogenic sample. Damodaran et al.[9] encapsulated single $C$. reinhardtii cells into millidroplets $(\sim 650 \mu \mathrm{m}$ diameter) and stored these for up to 140 hours in coiled tubing. Using chlorophyll fluorescence as a means of assessing cell growth, they found that within an isogenic population, there were subpopulations of fast and slow-growing cells. The contents of one 'fast-growing' droplet were then re-screened using the same technique, and the daughter population was also found to contain a range of fast and slow-growing cells. Investigation of the growth kinetics of $C$. vulgaris by Dewan et al. in microdroplets found that the growth profiles of different cells were highly heterogeneous, and cell size varied at different stages of the growth cycle [8].

\section{MICROFLUIDIC SCREENING OF MICROALGAL POPULATIONS FOR BIOTECHNOLOGY}

In order for microalgae to be used for applications in biotechnology, optimised species and strains need to be identified [63]. Microfluidic devices provide a platform to screen and sort microalgal populations. This might include screening environmental samples to identify a species of interest, or a mutagenized population of a promising species previously identified.

A key step in the development of microalgae as a feedstock for biofuels and other useful compounds is to identify and isolate strains that produce large amounts of the desired product. For biofuels in particular, engineered strains with maximized lipid content are a significant goal. Methods that quantify lipid content in algal samples are often slow and labour-intensive, requiring extraction from the cell, and analysis by thin-layer chromatography or gas chromatography (often coupled with flame ionisation detection or mass spectrometry) [64]. Whilst this is
A
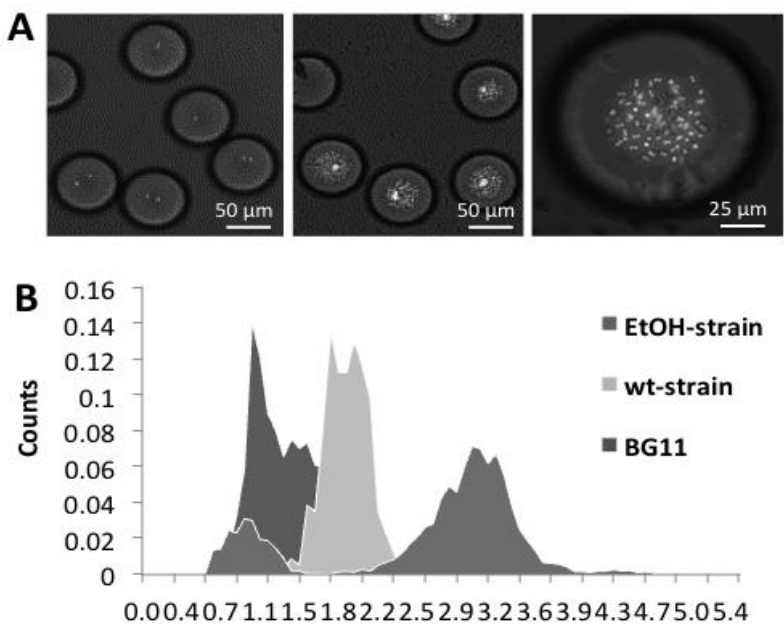

Fluorescence intensity (a.u.)

Figure 5. A) Fluorescence images of PCC6803 Synechocystis in microdroplets. From left to right: encapsulation at day 0 and at day 4 and a microdroplet containing grown cyanobacteria after 4 days of encapsulation at high magnification; B) Histogram showing the fluorescence intensity distribution of the microdroplets after ethanol assay in droplets. In dark-grey, pre-formed droplets containing the culture media (BG11); in light-grey, the fluorescence pattern obtained after encapsulating the wild-type strain; and in mid-grey, the two-populations profile obtained when encapsulating the ethanol-producing strain.

quantitative, it provides a low-throughput analysis of lipid extracts. An easier approach for monitoring lipid accumulation in microalgae is to stain neutral lipids using fluorescent dyes, such as Nile Red [65] and BODIPY [66,67], although this approach is less quantitative.

Indeed, both Nile Red and BODIPY staining has been used in high throughput lipid-based screening of algal populations to identify high lipid-yielding cells, both in fluorimeter-based assays [68] and flow cytometry coupled with Fluorescence Activated Cell Sorting (FACS) [69-75]. For example, Montero et al. have isolated Tetraselmis suecica with high lipid accumulation by using FACS. These lipophilic dyes can be used to stain individual cells and allow monitoring of lipid accumulation inside PDMS microfluidic devices, with the concomitant advantages of single-cell encapuslation. Several of the microfluidic chambers that were used to monitor growth of algae have also been used to track lipid accumulation [55-59,62] (See Table 1). Although this approach can be confounded by leakage of fluorescent stains into both the fluorinated oil carrier phase and the semipermeable PDMS [57-59], the problem can be addressed by coating the inner surfaces of the device with Bovine Serum Albumin (BSA) [57,58]. 
Table 1. Examples of studies of microalgae and cyanobacteria using microfluidic approaches. $*$ Number of cells.

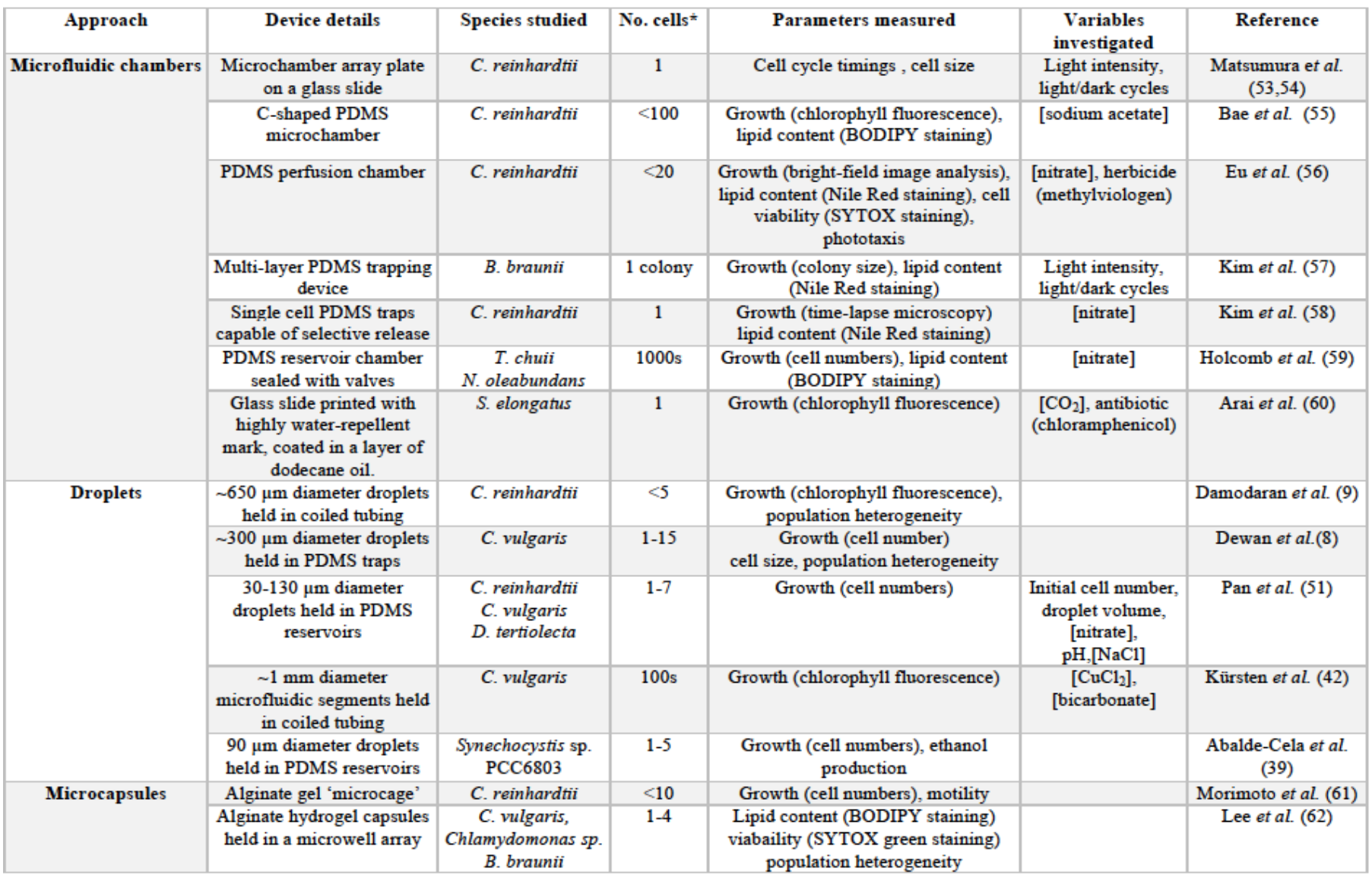

'Microfluidic cytometers' have been developed for highthroughput analysis of both microalgae and cyanobacteria as cheaper, smaller and less power-intensive alternatives to conventional flow cytometers [76-79]. Schaap et al. [19,80] studied different species of microalgae in a glass microfluidic chip and precisely measured the optical properties of each cell. Cells of different species and similar size displayed a characteristic distortion of the transmitted light depending on their geometry as they passed through a laser detector. Recently, it has been shown that microalgae and cyanobacteria can be both screened and sorted in microdroplets based on intrinsic chlorophyll fluorescence levels using a FADS-based approach. (Best et al. in preparation)

An important advantage of microdroplet technology and cell compartmentalization is that both the cell and its surrounding microenvironment can be screened at high throughput, allowing the fluorescence of molecules displayed on the cell surface, released into the surrounding medium or taken up from the droplet environment to be measured - something which cannot be performed using other microfluidic techniques [26], or indeed with FACS. Both consumption and secretion of metabolites to/from the cell media can be screened in droplets [40]. This has recently been exploited by Abalde-Cela et al. [41]. Transformed cyanobacteria capable of ethanol production and secretion were encapsulated into microdroplets, incubated off-chip for 48 hours then re-injected into a new microfluidic device. Reagents for a fluorescence-based ethanol assay were injected into each droplet, allowing for the screening of the encapsulated cells based on ethanol production at a rate of $100 \mathrm{~Hz}$ (Figure 5).

\section{CONCLUSIONS AND FUTURE PERSPECTIVES}

Microdroplets are an exciting technology platform that can be used in a variety of applications, including monitoring of growth characteristics at the single-cell level and highthroughput screening of algal populations. This technology has the potential to answer biological questions that cannot be tackled using bulk techniques. The platform will inevitably be expanded to include new species of both microalgae and cyanobacteria. It may then be used to assess how different parameters, such as light conditions, temperature or the carbon source available to cells, not only affect single-cell growth, but also the observed heterogeneity between cells across a culture. Moreover, in nature, microalgae exist in complex communities of several types of organisms. Following on from bacterial examples in which droplets are used to study cell-cell interactions, this technique would be useful for studying interactions between algal species or other community members at the single-cell level.

In the near future, microdroplet platforms will be a useful platform to determine individual cell characteristics to allow screening across a population, and thus to identify and select candidate cells for biotechnological feedstocks. The FADS technique can be applied to laboratory, environmental or mutagenized samples. The most obvious application will be 
screening and sorting cells based on their ability to accumulate large amounts of TAGs. Another likely application of the microdroplet screening and sorting methodology will be to screen and sort libraries of algal transformants. Using GFP or another fluorescent molecule as a selectable marker, rapid screening for successful transformants could be performed in microdroplets at high throughput and efficiency. As the potential of this emerging technical platform is recognized, the technology should become more accessible, so that it cansoon be adopted and used by researchers, without the need for specialized prior knowledge of microfluidics or expensive equipment.

\section{ACKNOWLEDGEMENTS}

SAC acknowledges the funding from EC within the EU FP7 DEMA project, grant agreement $n^{\circ} 309086$. RB was supported by a doctoral training grant from the Engineering and Physical Sciences Research Council (EPSRC) of the UK.

\section{REFERENCES}

[1] Scott SA, Davey MP, Dennis JS, Horst I, Howe CJ, Lea-Smith DJ, et al. Biodiesel from algae: challenges and prospects. Curr Opin Biotechnol 2010;21:27786.

[2] $\mathrm{Hu} \mathrm{Q}$, Sommerfeld M, Jarvis E, Ghirardi M, Posewitz M, Seibert M, et al. Microalgal triacylglycerols as feedstocks for biofuel production: perspectives and advances. Plant J 2008;54:621-39.

[3] Rodolfi L, Zittelli GC, Bassi N, Padovani G, Biondi N, Bonini G, et al. Microalgae for Oil: Strain Selection, Induction of Lipid Synthesis and Outdoor Mass Cultivation in a Low-Cost Photobioreactor. Biotechnol Bioeng 2009;102:100-12.

[4] Kaern M, Elston TC, Blake WJ, Collins JJ. Stochasticity in gene expression: from theories to phenotypes. Nat Rev Genet 2005;6:451-64.

[5] Elowitz MB, Levine AJ, Siggia ED, Swain PS. Stochastic gene expression in a single cell. Science 2002;297:1183-6.

[6] Newman JRS, Ghaemmaghami S, Ihmels J, Breslow DK, Noble M, DeRisi JL, et al. Single-cell proteomic analysis of S. cerevisiae reveals the architecture of biological noise. Nature 2006;441:840-6. to-cell heterogeneity in growth rate and gene expression in Methylobacterium extorquens AM1. J Bacteriol 2007;189:7127-33.

[8] Dewan A, Kim J, McLean RH, Vanapalli SA, Karim MN. Growth kinetics of microalgae in microfluidic static droplet arrays. Biotechnol Bioeng 2012;109:2987-96.

[9] Damodaran SP, Eberhard S, Boitard L, Rodriguez JG, Wang Y, Bremond N, et al. A Millifluidic Study of Cell-to-Cell Heterogeneity in Growth-Rate and Cell-Division Capability in Populations of Isogenic Cells of Chlamydomonas reinhardtii. PLoS One 2015;10:e0118987.

[10] Schubert C. Single-cell analysis: The deepest differences. Nature 2011;480:133-7.

[11] Whitesides GM. The origins and the future of microfluidics. Nature 2006;442:368-73.

[12] Barry R, Ivanov D. Microfluidics in biotechnology. J Nanobiotechnology 2004;2:2.

[13] Kim P, Kwon KW, Park MC, Lee SH, Kim SM, Suh KY. Soft lithography for microfluidics: a review. Biochip J 2008;2:1-11.

[14] Velve-Casquillas G, Le Berre M, Piel M, Tran PT. Microfluidic tools for cell biological research. Nano Today 2010;5:28-47.

[15] Groisman A, Lobo C, Cho H, Campbell JK, Dufour YS, Stevens AM, et al. A microfluidic chemostat for experiments with bacterial and yeast cells. Nat Methods 2005;2:685-9.

[16] Bao N, Wang J, Lu C. Recent advances in electric analysis of cells in microfluidic systems. Anal Bioanal Chem 2008;391:933-42.

[17] Voldman J. Electrical forces for microscale cell manipulation. Annu Rev Biomed Eng 2006;8:42554.

[18] Pearce TM, Wilson JA, Oakes SG, Chiu S-Y, Williams JC. Integrated microelectrode array and microfluidics for temperature clamp of sensory neurons in culture. Lab Chip 2005;5:97-101. 
[19] Schaap A, Bellouard Y, Rohrlack T. Optofluidic labon-a-chip for rapid algae population screening.

Biomed Opt Express 2011;2:658-64.

[20] Theberge AB, Courtois F, Schaerli Y, Fischlechner M, Abell C, Hollfelder F, et al. Microdroplets in microfluidics: an evolving platform for discoveries in chemistry and biology. Angew Chem Int Ed Engl 2010;49:5846-68.

[21] Rakszewska A, Tel J, Chokkalingam V, Huck WT. One drop at a time: toward droplet microfluidics as a versatile tool for single-cell analysis. NPG Asia Mater 2014;6:e133.

[22] Kintses B, van Vliet LD, Devenish SRA, Hollfelder F. Microfluidic droplets: new integrated workflows for biological experiments. Curr Opin Chem Biol 2010;14:548-55.

[23] Frenz L, Blank K, Brouzes E, Griffiths AD. Reliable microfluidic on-chip incubation of droplets in delaylines. Lab Chip 2009;9:1344-8.

[24] Schmitz CHJ, Rowat AC, Koster S, Weitz DA. Dropspots: a picoliter array in a microfluidic device. Lab Chip 2009;9:44-9.

[25] Courtois F, Olguin LF, Whyte G, Bratton D, Huck WTS, Abell C, et al. An integrated device for monitoring time-dependent in vitro expression from single genes in picolitre droplets. Chembiochem 2008;9:439-46.

[26] Mazutis L, Gilbert J, Ung WL, Weitz D a, Griffiths $\mathrm{AD}$, Heyman J a. Single-cell analysis and sorting using droplet-based microfluidics. Nat Protoc 2013;8:870-91.

[27] Baret J-C, Miller OJ, Taly V, Ryckelynck M, ElHarrak A, Frenz L, et al. Fluorescence-activated droplet sorting (FADS): efficient microfluidic cell sorting based on enzymatic activity. Lab Chip 2009;9:1850-8.

[28] Huebner A, Srisa-Art M, Holt D, Abell C, Hollfelder F, DeMello AJ, et al. Quantitative detection of protein expression in single cells using droplet microfluidics. Chem Commun 2007;12:1218-20.

[29] Song H, Ismagilov RF. Millisecond kinetics on a microfluidic chip using nanoliters of reagents. J Am
Chem Soc 2003;125:14613-9.

[30] Shim J, Olguin LF, Whyte G, Scott D, Babtie A, Abell C, et al. Simultaneous determination of gene expression and enzymatic activity in individual bacterial cells in microdroplet compartments. J Am Chem Soc 2009;131:15251-6.

[31] Mazutis L, Baret J-C, Treacy P, Skhiri Y, Araghi AF, Ryckelynck M, et al. Multi-step microfluidic droplet processing: kinetic analysis of an in vitro translated enzyme. Lab Chip 2009;9:2902-8.

[32] Granieri L, Baret J-C, Griffiths AD, Merten CA. High-throughput screening of enzymes by retroviral display using droplet-based microfluidics. Chem Biol 2010;17:229-35.

[33] Huebner A, Olguin LF, Bratton D, Whyte G, Huck WTS, de Mello AJ, et al. Development of quantitative cell-based enzyme assays in microdroplets. Anal Chem 2008;80:3890-6.

[34] Kumaresan P, Yang CJ, Cronier SA, Blazej RG, Mathies RA. High-throughput single copy DNA amplification and cell analysis in engineered nanoliter droplets. Anal Chem 2008;80:3522-9.

[35] Zeng Y, Novak R, Shuga J, Smith MT, Mathies RA. High-performance single cell genetic analysis using microfluidic emulsion generator arrays. Anal Chem 2010;82:3183-90.

[36] Chen F, Zhan Y, Geng T, Lian H, Xu P, Lu C. Chemical transfection of cells in picoliter aqueous droplets in fluorocarbon oil. Anal Chem 2011;83:8816-20.

[37] Zhan Y, Wang J, Bao N, Lu C. Electroporation of cells in microfluidic droplets. Anal Chem 2009;81:2027-31.

[38] Köster S, Angilè FE, Duan H, Agresti JJ, Wintner A, Schmitz C, et al. Drop-based microfluidic devices for encapsulation of single cells. Lab Chip 2008;8:1110-5.

[39] El Debs B, Utharala R, Balyasnikova I V, Griffiths $\mathrm{AD}$, Merten CA. Functional single-cell hybridoma screening using droplet-based microfluidics. Proc Natl Acad Sci U S A 2012;109:11570-5. 
[40] Wang BL, Ghaderi A, Zhou H, Agresti J, Weitz DA, Fink GR, et al. Microfluidic high-throughput culturing of single cells for selection based on extracellular metabolite production or consumption. Nat Biotechnol 2014;32:473-8.

[41] Abalde-Cela S, Gould A, Liu X, Kazamia E, Smith AG, Abell C. High-throughput detection of ethanolproducing cyanobacteria in a microdroplet platform. J R Soc Interface 2015;12:20150216.

[42] Churski K, Kaminski TS, Jakiela S, Kamysz W, Baranska-Rybak W, Weibel DB, et al. Rapid screening of antibiotic toxicity in an automated microdroplet system. Lab Chip 2012;12:1629-37.

[43] Miller OJ, El Harrak A, Mangeat T, Baret J-C, Frenz L, El Debs B, et al. High-resolution dose-response screening using droplet-based microfluidics. Proc Natl Acad Sci U S A 2012;109:378-83.

[44] Kürsten D, Cao J, Funfak A, Müller P, Köhler JM. Cultivation of Chlorella vulgaris in microfluid segments and microtoxicological determination of their sensitivity against $\mathrm{CuCl} 2$ in the nanoliter range. Eng Life Sci 2011;11:580-7.

[45] Boedicker JQ, Vincent ME, Ismagilov RF. Microfluidic Confinement of Single Cells of Bacteria in Small Volumes Initiates High-Density Behavior of Quorum Sensing and Growth and Reveals Its Variability. Angew Chemie-International Ed 2009;48:5908-11.

[46] Bai Y, Patil SN, Bowden SD, Poulter S, Pan J, Salmond GPC, et al. Intra-species bacterial quorum sensing studied at single cell level in a double droplet trapping system. Int J Mol Sci 2013;14:10570-81.

[47] Park J, Kerner A, Burns MA, Lin XN. Microdropletenabled highly parallel co-cultivation of microbial communities. PLoS One 2011;6:e17019.

[48] Jakiela S, Kaminski T. Bacterial growth and adaptation in microdroplet chemostats. Angew Chem Int Ed Engl 2013;52:8908-11.

[49] Clausell-Tormos J, Lieber D, Baret J-C, El-Harrak A, Miller OJ, Frenz L, et al. Droplet-based microfluidic platforms for the encapsulation and screening of Mammalian cells and multicellular organisms. Chem Biol 2008;15:427-37.
[50] Hufnagel H, Huebner A, Gülch C, Güse K, Abell C, Hollfelder F. An integrated cell culture lab on a chip: modular microdevices for cultivation of mammalian cells and delivery into microfluidic microdroplets. Lab Chip 2009;9:1576-82.

[51] Pan J, Stephenson AL, Kazamia E, Huck WTS, Dennis JS, Smith AG, et al. Quantitative tracking of the growth of individual algal cells in microdroplet compartments. Integr Biol (Camb) 2011;3:1043-51.

Joensson HN, Andersson Svahn H. Droplet microfluidics - a tool for single-cell analysis. Angew Chem Int Ed Engl 2012;51:12176-92.

[53] Matsumura K, Yagi T, Hattori A, Soloviev M, Yasuda K. Using single cell cultivation system for on-chip monitoring of the interdivision timer in Chlamydomonas reinhardtii cell cycle. J Nanobiotechnology 2010;8:23.

[54] Matsumura K, Yagi T, Yasuda K. Role of timer and sizer in regulation of Chlamydomonas cell cycle. Biochem Biophys Res Commun 2003;306:104210499.

[55] Bae S, Kim CW, Choi JS, Yang J-W, Seo TS. An integrated microfluidic device for the highthroughput screening of microalgal cell culture conditions that induce high growth rate and lipid content. Anal Bioanal Chem 2013;405:9365-74.

[56] Eu Y-J, Park H-S, Kim D-P, Wook Hong J. A microfluidic perfusion platform for cultivation and screening study of motile microalgal cells. Biomicrofluidics 2014;8:024113.

[57] Kim HS, Weiss TL, Thapa HR, Devarenne TP, Han A. A microfluidic photobioreactor array demonstrating high-throughput screening for microalgal oil production. Lab Chip 2014;14:141525.

[58] Kim HS, Devarenne TP, Han A. A high-throughput microfluidic single-cell screening platform capable of selective cell extraction. Lab Chip 2015;15:246775.

[59] Holcomb R, Mason L. Culturing and investigation of stress-induced lipid accumulation in microalgae using a microfluidic device. Anal Bioanal Chem 
2011.

[60] Arai S, Okochi M, Hanai T, Honda H. Microcompartmentalized cultivation of cyanobacteria for mutant screening using glass slides with highly water-repellent mark. Biotechnol Reports 2014;4:151-5.

[61] Morimoto Y, Tan W, Tsuda Y, Takeuchi S. Monodisperse semi-permeable microcapsules for continuous observation of cells. Lab Chip 2009;9:2217-23.

[62] Lee D-H, Bae CY, Han J-I, Park J-K. In situ analysis of heterogeneity in the lipid content of single green microalgae in alginate hydrogel microcapsules. Anal Chem 2013;85:8749-56.

[63] Pulz O, Gross W. Valuable products from biotechnology of microalgae. Appl Microbiol Biotechnol 2004;65:635-48.

[64] Davey MP, Horst I, Duong G-H, Tomsett E V, Litvinenko ACP, Howe CJ, et al. Triacylglyceride production and autophagous responses in Chlamydomonas reinhardtii depend on resource allocation and carbon source. Eukaryot Cell 2014;13:392-400.

[65] Chen W, Zhang C, Song L, Sommerfeld M, Hu Q. A high throughput Nile red method for quantitative measurement of neutral lipids in microalgae. $\mathrm{J}$ Microbiol Methods 2009;77:41-7.

[66] Cooper MS, Hardin WR, Petersen TW, Cattolico RA. Visualizing "green oil" in live algal cells. J Biosci Bioeng 2010;109:198-201.

[67] Govender T, Ramanna L, Rawat I, Bux F. BODIPY staining, an alternative to the Nile Red fluorescence method for the evaluation of intracellular lipids in microalgae. Bioresour Technol 2012;114:507-11.

[68] Li X, Moellering ER, Liu B, Johnny C, Fedewa M, Sears BB, et al. A galactoglycerolipid lipase is required for triacylglycerol accumulation and survival following nitrogen deprivation in Chlamydomonas reinhardtii. Plant Cell 2012;24:4670-86.

[69] Montero MF, Aristizábal M, García Reina G. Isolation of high-lipid content strains of the marine microalga Tetraselmis suecica for biodiesel production by flow cytometry and single-cell sorting. J Appl Phycol 2010;23:1053-7.

[70] Doan TTY, Obbard JP. Enhanced intracellular lipid in Nannochloropsis sp. via random mutagenesis and flow cytometric cell sorting. Algal Res 2012;1:1721.

[71] Benito V, Goñi-de-Cerio F, Brettes P. BODIPY vital staining as a tool for flow cytometric monitoring of intracellular lipid accumulation in Nannochloropsis gaditana. J Appl Phycol 2014;27:233-41.

[72] Manandhar-Shrestha K, Hildebrand M. Development of flow cytometric procedures for the efficient isolation of improved lipid accumulation mutants in a Chlorella sp. microalga. J Appl Phycol 2013;25:1643-51.

[73] Velmurugan N, Sung M, Yim SS, Park MS, Yang JW, Jeong KJ. Evaluation of intracellular lipid bodies in Chlamydomonas reinhardtii strains by flow cytometry. Bioresour Technol 2013;138:30-7.

Xie B, Stessman D, Hart JH, Dong H, Wang Y, Wright DA, et al. High-throughput fluorescenceactivated cell sorting for lipid hyperaccumulating Chlamydomonas reinhardtii mutants. Plant Biotechnol J 2014;12:872-82.

[75] Terashima M, Freeman ES, Jinkerson RE, Jonikas MC. A fluorescence-activated cell sorting-based strategy for rapid isolation of high-lipid Chlamydomonas mutants. Plant J 2014;81:147-59.

[76] Benazzi G, Holmes D, Sun T, Mowlem MC, Morgan H. Discrimination and analysis of phytoplankton using a microfluidic cytometer. IET Nanobiotechnol 2007;1:94-101.

[77] Hashemi N, Erickson JS, Golden JP, Jackson KM, Ligler FS. Microflow Cytometer for optical analysis of phytoplankton. Biosens Bioelectron 2011;26:4263-9.

[78] Hashemi N, Erickson JS, Golden JP, Ligler FS. Optofluidic characterization of marine algae using a microflow cytometer. Biomicrofluidics 2011;5:32009-320099.

[79] Erickson R, Jimenez R. Microfluidic cytometer for 
high-throughput measurement of photosynthetic

characteristics and lipid accumulation in individual algal cells. Lab Chip 2013;13:2893-291.
[80] Schaap A, Rohrlack T, Bellouard Y. Optical classification of algae species with a glass lab-on-achip. Lab Chip 2012;12:1527-32. 